\title{
Clinical Reasoning: A 40-year-old woman presenting with distal leg weakness
}

David Fam, MD, FRCPC, Raphael Schneider, MD, FRCPC, Julia Keith, MD, FRCPC, and Lorne Zinman, MD, MSc, FRCPC

Neurology ${ }^{\circledR}$ 2019;92:242-247. doi:10.1212/WNL.0000000000006859
Correspondence

Dr. Fam

david.fam@sunnybrook.ca

\section{Section 1}

A 40-year-old Caucasian woman reported 15 years of progressive lower leg and hand weakness. Weakness began asymmetrically in the legs. She had trouble standing on her toes and developed progressive bilateral foot drop, worse on the right. Over the years, she developed difficulty arising from low seats and climbing stairs. She began falling with her knees buckling bilaterally. She was a hairstylist, but stopped working about 2 years prior after the onset of weakness in her hands, including difficulty opening jars or using scissors. These symptoms progressed insidiously over the years without fluctuation.

The patient's medical history was unremarkable and she was not taking medications. Neurologic review of systems was negative for visual changes, dysphagia, dysarthria, pain, stiffness, sensory changes, or bowel/bladder dysfunction. She also denied dyspnea, myalgias, exercise intolerance, or myoglobinuria. All childhood developmental milestones were appropriate. Her parents were not consanguineous and there was no reported family history of weakness or symptoms of nerve or muscle disease.

On examination, the patient had short stature and a thin body habitus. She appeared comfortable with normal respiratory rate. Paradoxical breathing and accessory respiratory muscle use was not seen. Mental status was normal. Cranial nerve examination was normal. Speech was clear and palate elevated symmetrically. On motor examination, there was reduced muscle bulk in the distal legs including calves and tibialis anterior. Tone was normal in the arms and legs; no fasciculations were noted. She did not have action or percussion myotonia or scapular winging. Power on testing neck flexion was grade $4 / 5$. Strength testing in the limbs revealed the following (table): 1) disproportionate weakness of the great toe was not seen. The patient could not perform one-legged calf raises with either leg; 2 ) reflexes were $3+$ throughout except absent

Table Strength testing in the limbs

\begin{tabular}{|c|c|c|c|c|c|c|c|c|}
\hline Muscle & Deltoids & $\begin{array}{l}\text { Shoulder } \\
\text { external } \\
\text { rotation }\end{array}$ & Bicep & Triceps & $\begin{array}{l}\text { Finger } \\
\text { extensors }\end{array}$ & $\begin{array}{l}\text { First dorsa } \\
\text { interossei }\end{array}$ & $\begin{array}{l}\text { Flexor } \\
\text { pollicis } \\
\text { longus }\end{array}$ & $\begin{array}{l}\text { Long } \\
\text { finger } \\
\text { flexors }\end{array}$ \\
\hline Right & 5 & 5 & 5 & 5 & 4- & 4- & 4 & 4 \\
\hline Left & 5 & 5 & 5 & 5 & 4 & 4 & 5 & 5 \\
\hline Muscle & $\begin{array}{l}\text { Hip } \\
\text { flexors }\end{array}$ & $\begin{array}{l}\text { Hip } \\
\text { extensors }\end{array}$ & $\begin{array}{l}\text { Hip } \\
\text { abduction }\end{array}$ & $\begin{array}{l}\text { Knee } \\
\text { extension }\end{array}$ & $\begin{array}{l}\text { Knee } \\
\text { flexion }\end{array}$ & $\begin{array}{l}\text { Ankle } \\
\text { dorsiflexion }\end{array}$ & $\begin{array}{l}\text { Ankle } \\
\text { plantarflexion }\end{array}$ & $\begin{array}{l}\text { Extensor } \\
\text { hallucis } \\
\text { longus }\end{array}$ \\
\hline Right & 2 & 4- & 4- & 3 & 4- & 2 & $4+$ & 2 \\
\hline Left & 4- & 4 & $4+$ & 4 & 4 & 4- & $4+$ & \\
\hline
\end{tabular}

From the Department of Medicine, Division of Neurology (D.F., R.S., L.Z.), and Department of Anatomical Pathology (J.K.), Sunnybrook Health Sciences Centre, and Tanz Centre for Research in Neurodegenerative Disease (R.S.), University of Toronto, Canada.

Go to Neurology.org/N for full disclosures. Funding information and disclosures deemed relevant by the authors, if any, are provided at the end of the article. 
right patella and Achilles tendon reflexes. Sensation was normal to all modalities. Coordination was normal. Gait examination showed a steppage gait on the left.
Questions for consideration:

1. What localizations are possible in this case?

2. What testing would you recommend at this point?

GO TO SECTION 2 


\section{Section 2}

This patient appears to have a longstanding insidiously progressive pure motor syndrome involving mainly distal muscles in the upper extremities and a combination of proximal and distal muscles in the legs. The presence of pure motor symptoms favors localization to motor neuron, motor nerve, muscle, or neuromuscular junction. The weakness does not appear to be strictly myotomal and there are no convincing upper motor neuron signs.

Starting with the anterior horn, one consideration would be amyotrophic lateral sclerosis (ALS). Classic ALS is unlikely as there are no convincing upper motor neuron findings. The progressive muscular atrophy variant of ALS is also unlikely due to the very long clinical course and absence of bulbar involvement, cramping, and fasciculations. ${ }^{1}$ Longstanding slowly progressive motor neuron diseases such as adult-onset spinal muscular atrophy (SMA) should be considered. Weakness with preserved/brisk reflexes is inconsistent with SMA, which usually presents with symmetric proximally predominant weakness. However, one should recall that there are distal predominant forms of SMA. ${ }^{2}$

Motor nerve diseases such as multifocal motor neuropathy (MMN) often present with distal predominant weakness and could progress slowly over a period of years. Leg-onset MMN is rare as the legs are typically affected much less than the hands. ${ }^{3}$ Second, MMN typically produces weakness in the distribution of named nerves, which is not the pattern here. A motor predominant form of chronic inflammatory demyelination neuropathy is possible but patients usually have some sensory involvement and deep tendon reflexes are often absent. ${ }^{1}$

Neuromuscular junction disorders such as myasthenia gravis typically involve facial and bulbar muscles, proximal more than distal limb weakness, lack muscle atrophy, and show some degree of fluctuation. ${ }^{1}$

There are myopathies that could present distally, including myotonic dystrophy, facioscapulohumeral muscular dystrophy (FSHD), and inherited distal myopathies. The combination of distal arm weakness with proximal leg weakness raises the question of sporadic inclusion body myopathy (sIBM), but this is very uncommon in patients under age 50 and finger flexors are usually weak. ${ }^{4}$

Unenhanced MRI of the cervical, thoracic, and lumbosacral spine were normal. Routine chemistry including creatine kinase (CK) was normal. Additional bloodwork including GM1 antibodies, erythrocyte sedimentation rate, C-reactive protein, antinuclear antibodies, and thyroid-stimulating hormone was normal. Electrophysiologic studies revealed normal routine nerve conduction studies of the right arm and leg. EMG showed 1+ fibrillation potentials and low-amplitude, shortduration, polyphasic motor unit potentials with early recruitment in the right arm and leg. There were no myotonic discharges.

\section{Questions for consideration:}

1. What is the importance of the EMG results in terms of localization?

2. What additional testing would you order?

\section{GO TO SECTION 3}



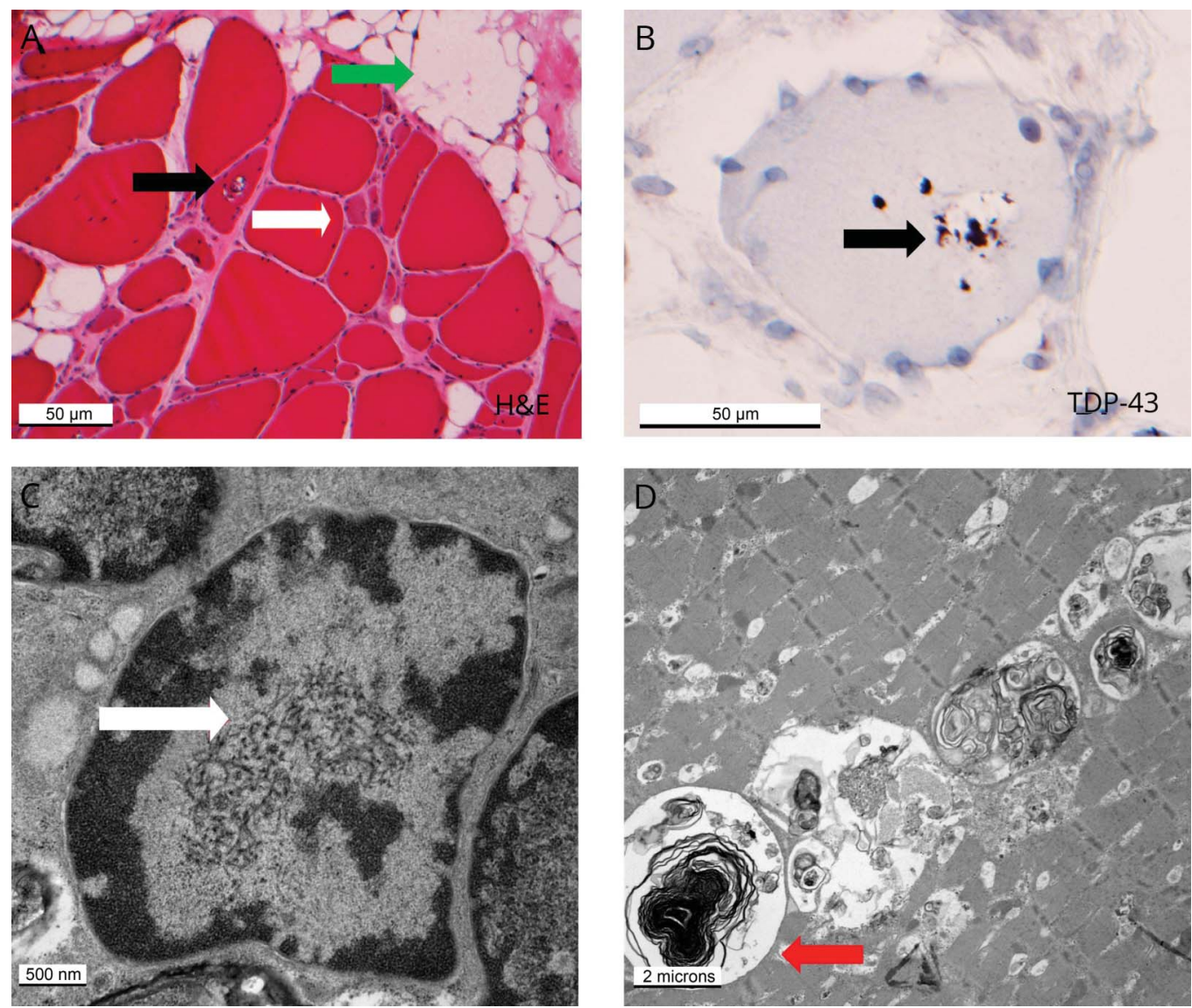

Muscle biopsy samples under light microscope (A, B) and electron microscope (C, D). (A) H\&E cross-section shows variability in fiber size and increased endomysial (white arrow) and adipose tissue (green arrow) with scant inflammation. The black arrow shows a rimmed vacuole. (B) Rimmed vacuole with p62 and TDP-43-positive inclusion (black arrow). (C) Ten- to fifteen-nanometer intranuclear granular and filamentous inclusions (white arrow) and (D) rimmed vacuole containing tubulovesicular material (red arrow). No protein aggregates, SDH/COX enzymatic discordance, or ragged-red fibers were seen and major histocompatibility complex was not upregulated.

\section{Section 3}

The EMG results are consistent with a myopathy and effectively exclude a neurogenic process. While fibrillations are seen in neurogenic processes, it is important to note that denervation occurs in myopathies because of segmental necrosis and muscle fiber splitting, leading to separation of the distal portion of the muscle fiber from the more proximal portion connected to the axon terminal. ${ }^{1}$

The patient's diagnosis is most consistent with a myopathy beginning with distal weakness in the anterior leg compartment resulting in early foot drop then progressing gradually to involve the proximal lower extremities and distal upper extremities. Myotonic dystrophy type 1 should always be considered as it is the most common distal predominant inherited myopathy in adults, but is unlikely in our patient for several reasons. First, patients with this disorder typically report stiffness secondary to myotonia with a characteristic facial appearance. The clinical examination and EMG would be expected to show myotonia, which was not seen. sIBM should be considered in a myopathy affecting long finger flexors and knee extension, but typically effects older patients. FSHD could start distally in the legs and be asymmetric, but scapular and proximal arm muscles are usually involved and the face is involved in approximately $90 \%$ of cases. ${ }^{5}$

The patient agreed to proceed with muscle biopsy of the left vastus lateralis and genetic testing (figure 1). ECG and echocardiogram were obtained and were normal. Genetic testing was conducted via a next-generation sequencing 18-gene distal myopathy panel. This was ultimately negative.

\section{Questions for consideration:}

1. Which distal myopathies would be likeliest in the context of the clinical presentation and biopsy findings?

2. What is the importance of the biopsy findings including the rimmed vacuoles? 


\section{Discussion}

Distal myopathies are mainly inherited myopathies causing weakness and atrophy of the distal arms and legs. ${ }^{4,5}$ Family history may be absent in cases with de novo sporadic mutations. ${ }^{5}$ Some genes are co-allelic with those causing limbgirdle muscular dystrophies. ${ }^{5}$ The distal myopathies also include many of the myofibrillar myopathies, a group of myopathies specifically affecting proteins of the myofibril (including sarcomere and $\mathrm{Z}$ disc proteins). Myofibrillar myopathies often have systemic features including cardiac and respiratory involvement. ${ }^{5,6}$

Most distal myopathies begin in the legs and involve either predominantly the anterior or posterior compartment, with considerable overlap. Some have a specific geographic predominance due to a population founder mutation. CK is often unhelpful in the diagnosis as it is often normal or only slightly elevated, with the exception of Miyoshi (dysferlinopathy), which often has a very elevated CK. MRI can be useful in narrowing down the differential diagnosis based on muscles affected. ${ }^{4,6}$ If a specific genetic cause is suspected, gene testing should be done before muscle biopsy. When choosing genes to test, careful consideration should be given to family history, ethnicity, age at onset, and clinical site of onset. Larger panels are also available to encompass broader testing (e.g., distal myopathy panel). If the genetic differential diagnosis is very broad, muscle biopsy may be required first.

This patient has a young age at symptom onset, which began distally with weakness worse in the anterior $>$ posterior leg compartment. Inherited distal myopathies more likely to produce this pattern would include hereditary inclusion body myopathy (hIBM), Laing myopathy (MYH7 mutation), and some myofibrillar myopathies. Laing myopathy (MYH7 mutation) often presents with disproportionate weakness of extensor hallucis longus and ankle dorsiflexors. This often produces a characteristic "hanging big toe." In this case, MYH7 testing was normal, excluding Laing myopathy.

Rimmed vacuoles can be seen in SIBM, but are nonspecific with a broad differential diagnosis including hIBM, myofibrillar myopathies, Udd myopathy, Welander myopathy, oculopharyngeal muscular dystrophy, and some limb-girdle muscular dystrophies. ${ }^{4}$ Cytoplasmic protein aggregates typical of myofibrillar myopathies were not observed. The combination of rimmed vacuoles, p62/TDP-43 immunopositive inclusions, and the intramyonuclear inclusions seen on electron microscopy are all consistent with sIBM, but the minimal inflammation and lack of major histocompatibility complex upregulation in this case were less than expected for sIBM. Altogether, the distal anterior predominant onset, patient age,

Figure 2 Clinical approach to inherited distal myopathy

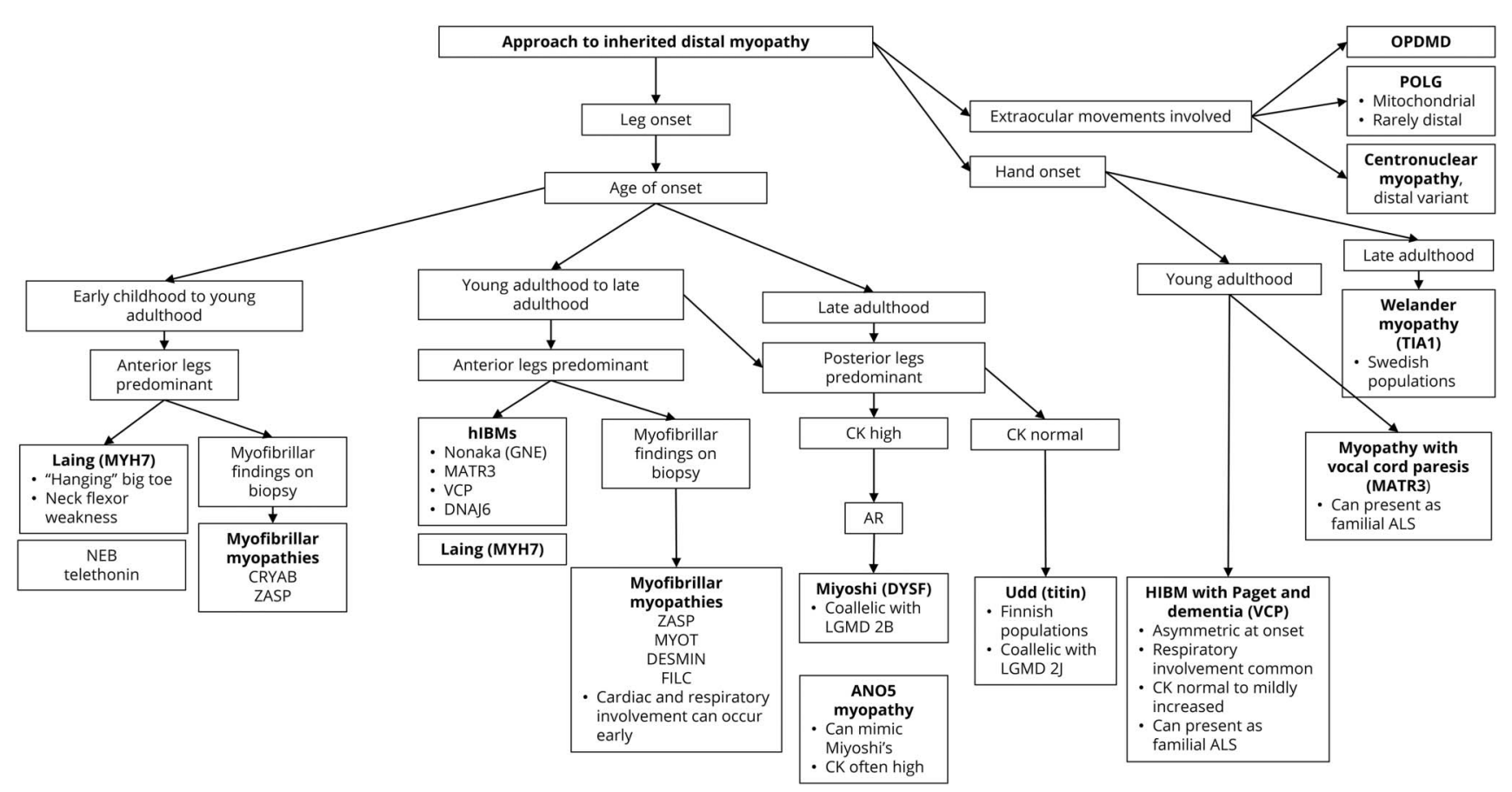

Myotonic dystrophy type 1 (not in figure) is the most common cause of adult-onset myopathy with distal onset weakness and should be considered in all cases. Most myopathies presented are autosomal dominant or sporadic with the exception of Miyoshi, anoctamin 5 (ANO5) myopathy, nebulin (NEB), and telethonin. Desmin and a $\mathrm{B}$ crystallin (CRYAB) myofibrillar myopathies can be dominant or recessive. Most distal myopathies have normal or mildly to moderately elevated creatine kinase (CK) with the exception of Miyoshi and ANO5 myopathy. ALS = amyotrophic lateral sclerosis; DYSF = dysferlin; FILC = Filamin C; hIBM = hereditary inclusion body myopathy; LGMD = limb-girdle muscular dystrophy; MYOT = myotilin; OPDMD = oculopharyngodistal muscular dystrophy; ZASP = Markesbery-Griggs myopathy. 
and biopsy results were thought to be more consistent with hIBM than IIBM. $^{8}$ sIBM cannot be excluded as rare cases with young onset and little inflammation on biopsy have been described.

hIBM can be differentiated from sIBM as the latter (1) typically presents at an older age, (2) more commonly has dysphagia, (3) often involves the quadriceps, (4) is more frequently asymmetric, (5) is more likely to have increased $\mathrm{CK}$, (6) and has more inflammatory/immune-related changes on biopsy. ${ }^{4,5,7}$ There are several types of hIBM. ${ }^{8}$ Nonaka myopathy (GNE mutation) often presents at a young age involving the distal anterior leg compartment. It is typically symmetric and rarely involves the quadriceps. ${ }^{5} \mathrm{CK}$ is often normal. Desminopathy has a similar phenotype, but is also a type of myofibrillar myopathy with characteristic biopsy findings including cytoplasmic desmin aggregates, not found here. In our case, genetic testing was negative for 3 genes known to cause hIBM: desmin, GNE, and VCP. Novel hIBM mutations are frequently being discovered and gene therapy may be available in the future. ${ }^{8-10}$ Clinicians should be aware of the most relevant genetic tests available to reach an accurate diagnosis (figure 2).

\section{Author contributions}

D.F., R.S., J.K., and L.Z. made substantial contributions to the study design and analysis of data. D.F. drafted the manuscript.
R.S., J.K., and L.Z. revised the manuscript critically for important intellectual content and gave final approval of the version to be published.

\section{Study funding}

No targeted funding reported.

\section{Disclosure}

The authors report no disclosures relevant to the manuscript. Go to Neurology.org/N for full disclosures.

\section{References}

1. Preston DC, Shapiro BE. Electromyography and Neuromuscular Disorders: ClinicalElectrophysiologic Correlations. Boston: Butterworth-Heinemann; 1998.

2. Tizzano EF, Finkel RS. Spinal muscular atrophy: a changing phenotype beyond the clinical trials. Neuromuscul Disord 2017;27:883-889.

3. Amato AA, Russell JA. Neuromuscular Disorders. New York: McGraw-Hill Medical; 2008.

4. Dimachkie MM, Barohn RJ. Distal myopathies. Neurol Clin 2014;32:817-842.

5. Pestronk A Distal myopathies. In: Washington Neuromuscular Homepage. Available at: neuromuscular.wustl.edu/musdist/distal.html. Accessed March 22, 2018.

6. Palmio J, Udd B. Myofibrillar and distal myopathies. Rev Neurol 2016;172: 587-593.

7. Kazamel M, Sorenson EJ, Milone M. Clinical and electrophysiological findings in hereditary inclusion body myopathy compared with sporadic inclusion body myositis. J Clin Neuromuscul Dis 2016;17:190-196.

8. Broccolini A, Mirabella M. Hereditary inclusion-body myopathies. Biochim Biophys Acta 2015;1852:644-650.

9. Wang H, Wu S. Novel valosin containing protein mutation in a Swiss family with hereditary inclusion body myopathy and dementia. Neuromuscul Disord 2015;25: 273.

10. Britson KA, Yang SY, Lloyd TE. New developments in the genetics of inclusion body myositis. Curr Rheumatol Rep 2018;20:26.

\section{Subspecialty Alerts by E-mail!}

Customize your online journal experience by signing up for e-mail alerts related to your subspecialty or area of interest. Access this free service by clicking on the "My Alerts" link on the home page. An extensive list of subspecialties, methods, and study design choices will be available for you to choose from-allowing you priority alerts to cutting-edge research in your field!

\section{Register Today for the 2019 Annual Meeting to Secure Best Rates}

Whether you're looking for innovative, high-quality science; customizable, experiential education and CME opportunities; or unparalleled networking within your community of 14,000+ neurology professionals from around the globe, the 2019 Annual Meeting in Philadelphia will offer unique, creative experiences in exciting and inspirational formats all week long to fuel your mind, body, and spirit. Secure your best rates by registering today at AAN.com/view/AM19. 


\section{Neurology}

Clinical Reasoning: A 40-year-old woman presenting with distal leg weakness

David Fam, Raphael Schneider, Julia Keith, et al.

Neurology 2019;92;242-247

DOI 10.1212/WNL.0000000000006859

This information is current as of January 28, 2019

\begin{tabular}{|c|c|}
\hline $\begin{array}{l}\text { Updated Information \& } \\
\text { Services }\end{array}$ & $\begin{array}{l}\text { including high resolution figures, can be found at: } \\
\text { http://n.neurology.org/content/92/5/242.full }\end{array}$ \\
\hline References & $\begin{array}{l}\text { This article cites } 7 \text { articles, } 0 \text { of which you can access for free at: } \\
\text { http://n.neurology.org/content/92/5/242. full\#ref-list-1 }\end{array}$ \\
\hline Subspecialty Collections & $\begin{array}{l}\text { This article, along with others on similar topics, appears in the } \\
\text { following collection(s): } \\
\text { All Education } \\
\text { http://n.neurology.org/cgi/collection/all_education } \\
\text { EMG } \\
\text { http://n.neurology.org/cgi/collection/emg } \\
\text { Muscle disease } \\
\text { http://n.neurology.org/cgi/collection/muscle_disease }\end{array}$ \\
\hline Permissions \& Licensing & $\begin{array}{l}\text { Information about reproducing this article in parts (figures,tables) or in } \\
\text { its entirety can be found online at: } \\
\text { http://www.neurology.org/about/about_the_journal\#permissions }\end{array}$ \\
\hline Reprints & $\begin{array}{l}\text { Information about ordering reprints can be found online: } \\
\text { http://n.neurology.org/subscribers/advertise }\end{array}$ \\
\hline
\end{tabular}

Neurology ${ }^{\circledR}$ is the official journal of the American Academy of Neurology. Published continuously since 1951, it is now a weekly with 48 issues per year. Copyright @ 2019 American Academy of Neurology. All rights reserved. Print ISSN: 0028-3878. Online ISSN: 1526-632X.

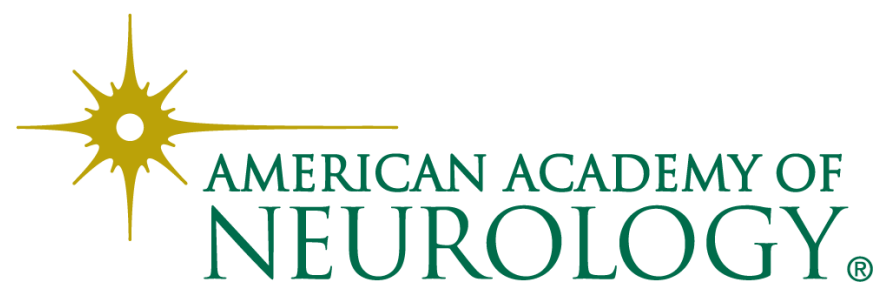

